\title{
The Relationship Between the Concrete Strength Values of Curing Specimens Using Microwave and Standard Methods
}

\author{
Zhiyong TIAN ${ }^{\text {a }}$, Yuxuan YANG ${ }^{\text {b }}$, Hongtao PENG ${ }^{\text {a, }}$, , Jiahui HUANG ${ }^{\text {a }}$, Yihua ZHOU ${ }^{\text {a }}$, \\ Mengyang $\mathrm{YU}^{\mathrm{a}}$, Baifeng $\mathrm{LI}^{\mathrm{a}}$ and Han $\mathrm{GAO}^{\mathrm{a}}$ \\ ${ }^{a}$ College of Water Resources and Civil Engineering, China Agricultural University, \\ Beijing 100083, People's Republic of China \\ ${ }^{\mathrm{b}}$ The Organization Department of Wenxi County CPC Committee, Shanxi 043800 \\ People's Republic of China
}

\begin{abstract}
As the most widely used construction material, concrete has the characteristics of good compressive performance. The compressive strength of concrete is the most important performance index. However, the compressive strength of concrete measured is generally based on the standard curing period for $28 \mathrm{~d}$. Its period for detection is long. Therefore, it is necessary to study a fast and effective detection method. This paper mainly introduces the experimental method of microwave curing concrete and the relationship between concrete strength values of curing specimens using microwave and standard methods. The experimental results show that concrete specimens exposed to accelerated curing condition under microwave irradiation can increase the strength quickly within a shorter time period depending upon the procedure used in this work. By analysing experimental data, a model of concrete strength at age of $28 \mathrm{~d}$ using microwave curing and standard curing methods is established, which can early estimate compressive strength of concrete and provide a quick method for measuring the strength in the field.
\end{abstract}

Keywords. Concrete, compressive strength, microwave curing method, accelerated curing condition, curing period

\section{Introduction}

As one of the most important and widely used building materials, concrete has attracted much attention. The strength of concrete has always been the focus of attention. The evaluation of concrete strength in Chinese civil engineering industry is generally based on the "standard for evaluation of concrete compressive strength" (GB/T50107-2010), and whether the design requirements can be met is mainly based on the standard test parts of the cube with a standard production size of $150 \mathrm{~mm} * 150 \mathrm{~mm} * 150 \mathrm{~mm}$ under standard maintenance conditions of 28 day [1]. Because of this, the strength of concrete must be known after $28 \mathrm{~d}$ of concrete pouring. This causes the staff to be unable to evaluate the quality of concrete in the short term and to determine whether the strength of concrete meets the construction requirements. Therefore, a rapid method for

\footnotetext{
${ }^{1}$ Hongtao Peng, College of Water Resources and Civil Engineering, China Agricultural University, Beijing 100083, People's Republic of China; E-mail: pwb@cau.edu.cn.
} 
measuring concrete is needed. At present, the methods of quick determination of concrete strength are: boiling water method, hot water method, warm water method, pressure steam method and early age method [2].

In the 1990s, researchers Leung and Pheeraphan, from Cambridge, UK, studied new methods of developing early concrete strength and found that microwave conservation could greatly improve the early strength of concrete. Microwave heating has the characteristics of fast heating speed and uniform heating. Therefore, it has great research value to use microwave curing to predict the standard strength of concrete. There are also related aspects of experimental research in China. In 2001, Yang and Wen [3] proposed that microwave curing concrete can improve the early strength of the specimen without compromising the strength of $28 \mathrm{~d}$,, And the key lies in good temperature control, including keeping the internal temperature of the product constant, to avoid overheating and other undesirable phenomena inside the product. In 2004, Zhao and $\mathrm{Du}$ [4] experimented with microwave-heated concrete, and it was concluded that microwave maintenance could obtain higher early strength and shorten the time required for demoulding. Test block can reach more than $10 \mathrm{MPa}$ in a matter of hours, but microwave maintenance can also reduce the long-term strength of the test pieces to some extent. In 2009, Wang [5] studied the microwave curing concrete test block and found that the absorption of microwave energy by different proportions of cement slurry was different, and the rate of energy absorption increased as the water-grey ratio increased. Comparison of test block strength under microwave and standard curing conditions, microwave curing test block can promote hydration of cement, so that the test block can obtain higher strength in a short time. In 2011, Sun [1] studied the strength prediction of high-performance concrete by microwave curing. In 2014, Yu and $\mathrm{Lu}$ [6] used microwave heating to predict the later strength of concrete. In 2019, Gao and $\mathrm{Li}$ [7] studied the effect and mechanism of microwave curing on the mechanical properties of ultra-high performance concrete. Based on the design strength of $30 \mathrm{MPa}$ concrete, this paper establishes a reasonable microwave conservation system, and studies the relationship between microwave maintenance and standard maintenance concrete.

\section{Experimental Principle}

Microwave is an electromagnetic wave with a wavelength in the $1 \mathrm{~mm}-1 \mathrm{~m}$ range and its frequency is between $300 \mathrm{GHz}$ and $300 \mathrm{MHz}$. In a magnetic field, the molecules of some substances are polarized. As the direction of the magnetic field changes hundreds of millions of times per second, polar molecules always try to adjust their orientation at the same rate, resulting in violent movement and friction collision of molecules. This results in direct conversion of electrical energy to heat, resulting in material heating. The newly made concrete test blocks contain a large number of water molecules, which are strong polar molecule and the best medium for absorbing microwave. When the concrete test block is in the magnetic field, because of the existence of water molecules, a large amount of microwave energy is absorbed and converted into heat energy, which can make the concrete heat up quickly and accelerate the hydration reaction of concrete. The strength of microwave curing can be obtained in a short time. Then, the algebraic relationship between the two is established by comparing the strength of concrete under the maintenance of the same batch of standard conditions. This provides a new early method for predicting concrete strength. 


\section{Experimental Overview}

The microwave oven with frequency $2.45 \mathrm{GHz}$, maximum power $800 \mathrm{~W}$ is used as the microwave curing experimental box. The design strength of concrete in the experiment is $30 \mathrm{MPa}$, and the size of concrete test block is $100 * 100 * 100 \mathrm{~mm}^{3}$.

\subsection{Experimental Process}

The experimental processes are as follows: determining the mix ratio; calculating and weighing raw materials; making concrete test blocks; microwave curing and standard curing respectively; testing the compressive strength of concrete.

The mix ratio of concrete in the experiment is shown in table 1.

Table 1. The mix ratio of concrete $\left(\mathrm{kg} / \mathrm{m}^{3}\right)$

\begin{tabular}{llllllll}
\hline Water & Cement & Fly ash & $\begin{array}{l}\text { Ore } \\
\text { powder }\end{array}$ & Sand & Fine stones & $\begin{array}{l}\text { Rough } \\
\text { stones }\end{array}$ & Admixture \\
\hline 168 & 250 & 100 & 50 & 785.9 & 354.56 & 531.84 & 4 \\
\hline
\end{tabular}

\subsection{Manufacture of Concrete Test Blocks}

Each experiment produced 5 pieces of concrete of $100 * 100 * 100 \mathrm{~mm}^{3}$, two of which were for microwave curing and three for standard curing.

\subsection{Curing Methods}

Through the pre-experiment, it is determined that the microwave curing system is to place the freshly mixed concrete test block in the microwave oven. First, the internal temperature of the concrete test block reaches about $70^{\circ} \mathrm{C}$ when it is heated continuously for about $45 \mathrm{~min}$. Then keep the temperature at $70 \pm 5{ }^{\circ} \mathrm{C}$ and heat continuously for $6 \mathrm{~h}$. Microwave curing places the concrete test block at $20 \pm 5^{\circ} \mathrm{C}$ temperature, keeps the relative humidity above $95 \%$ in the curing room, and maintains for $28 \mathrm{~d}$ continuously and then tests its $28 \mathrm{~d}$ compressive strength.

\section{Analysis of Experimental Data}

Taking the average strength of microwave curing and standard curing concrete in each group of experiment. The experimental data are summarized in table 2.

Table 2. Strength of concrete specimens under microwave and standard curing (MPa).

\begin{tabular}{lll}
\hline Group & Strength of microwave curing/MPa & $\begin{array}{l}\text { Strength of using standard curing } \\
\text { methods for } 28 \text { days/MPa }\end{array}$ \\
\hline 1 & 6.9 & 28.4 \\
2 & 7.3 & 37.4 \\
3 & 8.6 & 36.8 \\
4 & 8.8 & 33.7 \\
5 & 7.1 & 25.3 \\
6 & 8.3 & 35.7
\end{tabular}




\begin{tabular}{lll}
\hline Group & Strength of microwave curing/MPa & $\begin{array}{l}\text { Strength of using standard curing } \\
\text { methods for 28 days/MPa }\end{array}$ \\
\hline 7 & 9.7 & 37.7 \\
8 & 9.3 & 24.8 \\
9 & 7.2 & 28.6 \\
10 & 7.6 & 28.2 \\
11 & 8.7 & 32.2 \\
12 & 8.7 & 33.7 \\
13 & 7.4 & 28.4 \\
14 & 8.6 & 37.5 \\
15 & 7.2 & 29.3 \\
16 & 7.1 & 25.3 \\
17 & 8.3 & 35.7 \\
18 & 9.9 & 35.6 \\
19 & 6.6 & 27.3 \\
20 & 7.1 & 32.5 \\
\hline
\end{tabular}

Assuming that microwave curing concrete strength prediction concrete standard strength relationship should meet the following equations.

$$
\begin{aligned}
& f_{c u}^{e}=a f_{c u}^{w}+b \\
& a=\frac{\sum_{i=1}^{n}\left(f_{c u . i} f_{c u . i}^{w}\right)-\frac{1}{n} \sum_{i=1}^{n} f_{c u . i} \sum_{i=1}^{n} f_{c u . i}^{w}}{\sum_{i=1}^{n}\left(f_{c w . i}^{w}\right)^{2}-\frac{1}{n}\left(\sum_{i=1}^{n} f_{c u . i}^{w}\right)^{2}} \\
& \mathrm{~b}=\frac{1}{n} \sum_{i=1}^{n} f_{c u . i}-\frac{a}{n} \sum_{i=1}^{n} f_{c u . i}^{w}
\end{aligned}
$$

$\boldsymbol{f}_{\boldsymbol{c u}}^{\boldsymbol{e}}$ : Standard curing concrete $28 \mathrm{~d}$ strength prediction (MPa)

$\boldsymbol{f}_{\boldsymbol{c u}}^{\boldsymbol{w}}$ : Microwave curing concrete strength (MPa)

$\boldsymbol{f}_{\boldsymbol{c u} . i}$ : No Group standard curing concrete 28 days strength (MPa)

$\boldsymbol{f}_{c u . i}^{w}$ : No Group microwave curing concrete strength (MPa)

$\mathrm{n}$ : Number of experimental groups

a, b: Regression coefficient

The relationship between microwave curing strength and standard strength of concrete is as follows:

$$
\boldsymbol{f}_{c u}^{e}=2.44 \boldsymbol{f}_{c u}^{w}+12.16
$$

$\boldsymbol{f}_{\boldsymbol{c} \boldsymbol{e}}^{\boldsymbol{e}}$ : Standard curing concrete $28 \mathrm{~d}$ strength prediction (MPa)

$\boldsymbol{f}_{\boldsymbol{c} u}^{\boldsymbol{w}}$ : Microwave curing concrete strength (MPa)

Microwave heating curing concrete, the temperature of concrete changes with time as shown in figure 1. 


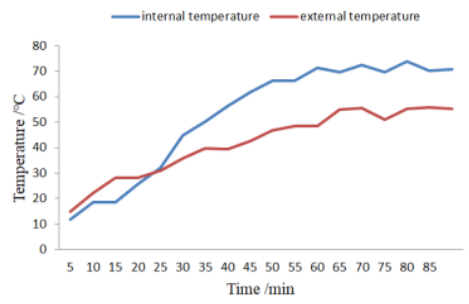

Figure 1. Relationship between temperature and time.

It can be seen from the diagram that the internal temperature of the freshly mixed concrete test block is lower than the surface temperature, and the internal temperature increases faster than the external temperature as the temperature of the heated concrete test block begins to increase. After about 20 minutes of heating, the internal temperature is higher than the external temperature. During the later heating process, the internal temperature is about $15^{\circ} \mathrm{C}$ higher than the external temperature.

\section{Conclusions}

Microwave curing concrete can obtain microwave strength in a short time. Microwave heating concrete has the characteristics of fast heating speed and uniform heating.

At the stage of continuous heating, the internal temperature of concrete increases faster than that of external temperature. In the stage of constant temperature heating, the internal temperature of concrete is about $15^{\circ} \mathrm{C}$ higher than that of external temperature.

The strength of concrete can reach about $8 \mathrm{MPa}$ after $6.5 \mathrm{~h}$ of microwave curing concrete. The relationship between microwave curing strength and standard curing $28 \mathrm{~d}$ concrete strength $\boldsymbol{f}_{c u}^{e}=2.44 \boldsymbol{f}_{c u}^{w}+12.16$.

\section{References}

[1] Sun DM. Concrete microwave coagulation experiment research. Master's thesis. Harbin: Harbin University of Engineering, 2011. 61p.

[2] Ministry of Housing and Urban-Rural Development of the People's Republic of China. Standard for test method of early estimating compressive strength of concrete. JGJ/T15-2008. Beijing: China Architecture \& Building Press; 2008. 21 p.

[3] Yang YB, Wen ZY. Microwave conservation technology for cement-based materials low temperature. Building Technology. 2001 Sep; (3): 63-65.

[4] Zhao Q, Du JF. Microwave conservation concrete test. Shanxi Architecture. 2004 Dec; (24): 100-101.

[5] Wang YL. Experimental study on the effect of microwave heating on the strength of cement net slurry. Master's thesis. Tangshan: Hebei Polytechnic University. 2009. 57p.

[6] Yu L, Lu D. Early prediction of concrete strength using microwave heating maintenance. Shanxi Architecture. 2014 Dec; 40(34): 118-121.

[7] Gao XJ, Li SX. Effects of Microwave curing on the mechanical properties of ultra-high performance concrete and affecting mechanism. Materials Reports. 2019 Jan; 33(2): 271-276. 